\title{
Acoustic Strength of Green Turtle and Fish Based on FFT Analysis
}

\author{
Azrul Mahfurdz,Sunardi, Hamzah Ahmad \\ Faculty of Electrical and Electronics Engineering \\ University Malaysia Pahang (UMP) \\ 26600 Pekan, Malaysia
}

\author{
Syed Abdullah Syed Abdul Kadir,Nazuki Sulong \\ Turtle and Marine Ecosystem Center (TUMEC) \\ Malaysia Fisheries Department \\ Rantau Abang, 23050 Dungun, Malaysia
}

\begin{abstract}
- the acoustic power at difference angle and distance were measure for four different ages of Green Turtles and three species of fish using modified echo sounder V1082. The echo signal from TVG output was digitized at a sampling rate $1 \mathrm{MHz}$ using analog to digital converter (Measurement Computing USB1208HS). Animals were tied with wood frame to ensure it can't move away from the sound beam. The scatter value for fish demonstrates echo strength is different and depends on the angle of measurement. The lowest acoustic power of fish was recorded from their tail. The finding show that, there is significant difference between fish and turtles aged 12 to 18 years at 4.5 meter and 5 meter. The carapace and plastron of sea turtle gives high backscattering strength compare to other side. The high value obtained probably because of the hard surface of the carapace and plastron. This result is considered important in determining the best method of separating sea turtle and fish. Through this result, revealed that size, surface and animal angle play important role in determining acoustic strength value.
\end{abstract}

Keywords-Echosounder; Green Turtle; acoustic power; TED

\section{INTRODUCTION}

Sea turtles are marine reptiles that can be found live throughout the world tropical and subtropical seas. Sea turtles can be threatened by several factors, some natural and others caused by human activities.

Over the last few centuries, sea turtle populations have declined dramatically due to various activities such as shore development, oil exploration, commercial fishing, marine recreation and pollution.

By catch in fisheries activities has been determined to be a major factor of death for juvenile and adult sea turtles [1][2]. For several years now we have heard large numbers of turtle taken in fisheries net. Report from Japanese fisheries an estimated 40,000 sea turtles of three species were caught and 16,000 dead in the Japanese tuna long line fleet in the pacific [3].

Interview with six islander drift net vessel owner and operators in Malaysia reported 140 turtle were caught annually in 2005 to 2006. Green and Hawksbill species were report to be most frequently caught [4].

By catch of sea turtles in shrimp fisheries in tropical areas attracted more public concern especially problems related to by catch in trawl fisheries. This issue has had wide political and economic impacts on global fisheries and trade [5].
Although there are method avoiding turtle trap in fisheries net like gear modification, material and fishing method [4], but that method need cooperation between the fisherman to modify their vessel and change fishing method.

To address this problem, National Marine Fisheries Service (NMFS) suggested every shrimp trawler larger than 25 feet to use a turtle excluder device (TED) [6]. The process of reducing the incidental capture of sea turtles in regional shrimp fisheries through the use of TED has been extremely important [7].

A solution technique to separate turtles from shrimps in trawl was available by the early 1980 [8]. A traditional TED generally consists of metal grids that have been installed in a trawling net to enable endangered sea turtles to pass safely out of the net through a trapdoor [9]. Although metal grid TED method gives the solution to protect sea turtle but this method may reduce number of fish and shrimp catches [2]. The reports using TED with and without accelerator funnels were cause shrimp loss rates of 3.6 and 13.6 percent respectively [9].

The observation vessel equipped with TED found that highest reduction in prawn catch occurred during tows through areas with large amounts of star fish, sponges, sea urchins, sea cucumber and benthic debris. Catch loss occurred as a result starfish blocking the grid or tangling the guiding flap, causing inefficient operation [10].

The traditional TED consist metal trap door in trawling net seen not efficient solution for reducing turtle by catch, because it would exclude the larger commercial specimens [11].

Therefore the improvement of TED is needed in order to ensure the device use to separate endangered species can be used effectively. One of the alternative solution is suggested using sound technique [12][13].

Although the using of ultrasound is capable to prevent turtles from entering the fishing net, the alert sound will be emitted all the time. This situation will lead to wastage of power and disturb other marine live that also sensitive to the sound

To overcome this problem, the device should be able detect the presence of sea turtle. By this method sounds are emitted only after the device was able to identified sea turtle. One of the best ways in detecting underwater object is using acoustic technique. This technique has been choosing because of the sound's ability to propagate long distance in water [14]. 
The knowledge on turtle identification using sound is very limited in previous study. So the acoustic strength of the sea turtle in this study becomes important on designing electronic turtle excluder device.

\section{MARine Life Detection Using SOUND}

Sound technique has been widely used in various fields to identify objects in the water. These applications include tracking underwater vehicle, aquatic vegetation detection and fisheries research.

The device used to observe marine animal called echo sounder. These tools are widely used to detect the distribution of fish. Basically, acoustic echo sounders have operated at frequencies in the tens to hundreds of kilohertz [15].

Aquatic organisms are complicated scatter by nature through shape, size, orientation, swim bladder and so on [16]. Smaller animals have lower echo strengths and larger animals have higher echo strengths [17][18].

The presence of swim bladder in fish body is the primary biological factor influencing the amount and variability of backscattering sound from fish [19]. Natural variations in swim bladder volume and shape may cause variation in fish echo. Understanding scattering strength of the swim bladder is important factor to study fish school. The echo waveform is different depends on orientation of fish and strongest echo occurred when the incident signal was perpendicular to the swimbladder [20].

Acoustic strength for mammals like whale may be depending on their lung and blubber layer [21]. Other than that, Dolphins have a combination of unique scattering characteristics that makes it possible to separate them from other animal. Stronger echoes, expected from their lung [22].

There are many approaches to modeling the scattering of sound by objects. The particular approach depends upon the shape and material properties of the body [23]. Study on acoustic strength of the shelled animal quite challenge because involved a variety of body shapes and biology properties, so their acoustic scattering characteristic is sometimes very complicated [24].

The scattering process of the animals was observed to be quite complex as the echoes were strongly dependent upon both frequency and angle of orientation [25][26].

Scattering from elastic shelled animal like periwinkles is characterized by a very strong echo reflected by their hard shell and also angle of orientation [27]. Moreover, study on acoustic scattering by a shell covered seafloor discovered that shellfish played an important role scattering seafloor [25].

Studies on the sea turtle are very limited because there are no acoustic characteristic of that animal recorded. However, study on fresh water turtle discovered that it can be detecting using echo sounder and the high backscattering strength is from their shell [28].

This finding has paved a way to differentiate echo strength between sea turtle and fish, which is sharing same habitat in the sea.

\section{EXPERIMENT PROCEDURE}

The acoustic data collection were conducted in Turtle and Marine Ecosystem Center hatchery, Rantau Abang Terengganu, Malaysia.The marine animals that have been involved in this study were four Green Turtles (Chelonia Mydas) and three species of fish as listed in Table I.The experiment conducted in a $13 \mathrm{~m} \times 2.4 \mathrm{~m}$ rectangular tank contained 8235.68 gallons saline water. Animals were tied with wood frame as depicted in Fig. 1, to ensure it can't move away from the sound beam. The frame has been designed to make sure it is able to measure turtle at the different angle.

TABLE I. ANIMAL INVOLVED IN EXPERIMENT

\begin{tabular}{|c|c|c|c|}
\hline \multirow{4}{*}{ Animal } & Age & Weight & $\begin{array}{c}\text { Carapace } \\
\text { size }\end{array}$ \\
\hline \multirow{3}{*}{ Green Turtle } & 1 year & $1.8 \mathrm{~kg}$ & $25 \mathrm{~cm} \times 23 \mathrm{~cm}$ \\
\cline { 2 - 4 } & 5 years & $10 \mathrm{~kg}$ & $43 \mathrm{~cm} \times 41 \mathrm{~cm}$ \\
\cline { 2 - 4 } & 12 years & $27 \mathrm{~kg}$ & $61 \mathrm{~cm} \times 56 \mathrm{~cm}$ \\
\cline { 2 - 4 } & 18 years & $60 \mathrm{~kg}$ & $71 \mathrm{~cm} \times 61 \mathrm{~cm}$ \\
\hline \multirow{3}{*}{ Fish } & \multicolumn{2}{|c|}{ Species } & Body Size \\
\cline { 2 - 4 } & \multicolumn{2}{|c|}{ Indian Mackerel } & $19 \mathrm{~cm} \times 4.5 \mathrm{~cm}$ \\
\cline { 2 - 4 } & \multicolumn{2}{|c|}{ Indian Scad } & $18 \mathrm{~cm} \times 4 \mathrm{~cm}$ \\
\cline { 2 - 4 } & \multicolumn{2}{|c|}{ Bigeye Scad } & $21.5 \mathrm{~cm} \times 5.2 \mathrm{~cm}$ \\
\hline
\end{tabular}

There are five different angles of measurement for green turtle (head, tail, side, carapace \& plastron) and three angles for fish (head, lateral and tail). Reflected signal from animals were measure at 1 meter to 5 meter distances. Sea turtles will be lifted to the surface every 15 minutes to breathe, it is importapt to avoid drowning in the water.

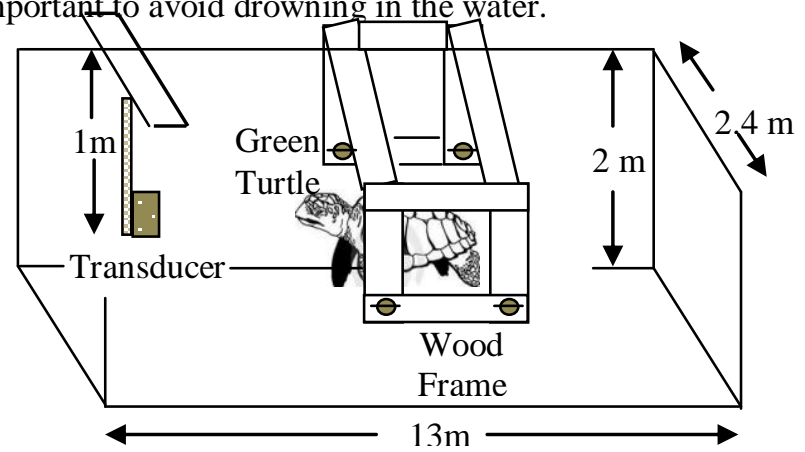

Fig. 1. Sea turtle attach with wood frame to ensure the turtle can't move away from the sound beam.

Modified dual frequency echo sounder V1082 used in this research. The signal is taken from TVG output and connected to the high speed analog digital converter (Measurement Computing USB-1208HS). The envelope of the echo was digitized at a sampling rate $1 \mathrm{MHz}$ using echo recording program created in matlab software. The total of 6525 random sample of sound has been recorded and store in laptop. There are several things to be considered before experiment was carried out such as echo reflection from tanks, operating frequency and sound speed. Therefore, device should be handling and setting properly. The echosounder parameters setting involved in this study are shown in Table II. 
TABLE II. ECHOSOUNDER PARAMETER SETTING

\begin{tabular}{|l|c|}
\hline \multicolumn{1}{|c|}{ Parameter } & Setting \\
\hline Frequency & $200 \mathrm{kHz}$ \\
\hline Gain & $35 \mathrm{~dB}$ \\
\hline Noise Reduction & Low \\
\hline Echo Level & 7 \\
\hline STC & 4 \\
\hline Dynamic Ring & $5 \mathrm{~dB}$ \\
\hline
\end{tabular}

\section{DATA ANALYSIS AND RESUlT}

The acoustic characteristics of the empty frame were measure before it has been attach to green turtle and fish. Visual observation of the echogram revealed that maximum detection without interference is five meter. Therefore, the measurement carries out in this research limited to five meter distance.

The primary objectives of this study were to compare acoustic power backscatter from sea turtle and fish. Sound sample was analysed in time and frequency domain using matlab program. Despite the sounds of 6525 samples were recorded, only 580 of them can be used in the analysis. The example echo waveform is depicted in Fig. 2.

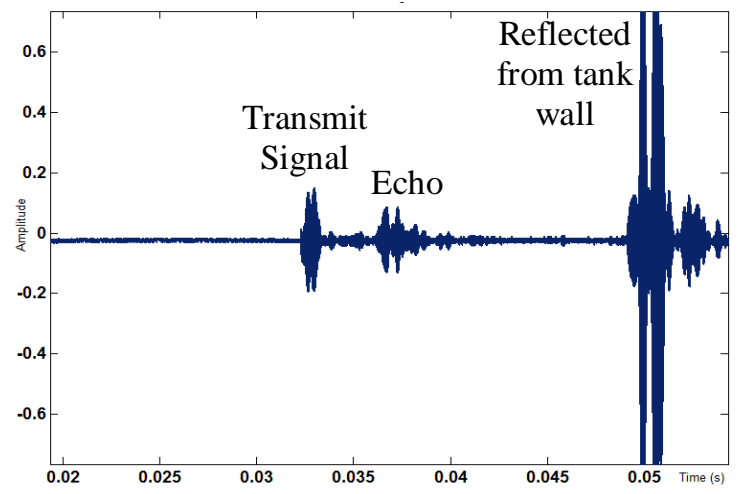

Fig. 2. Envelope echo signal in time domain.

A sound wave received from TVG output contains a transmitter and echo signal. To investigate the power spectrum in the frequency domain, each transmitted signal must be removed first, to ensure that the values obtained contains only the reflected signal from the object. The total number FFT calculated is 8192 point and power value is taken from the highest magnitude peak starts at frequency $450 \mathrm{KHz}$ to 460 KHz. The power spectrum and magnitude point involved in calculating echo power of the green turtle and fish is shown in Fig. 3.

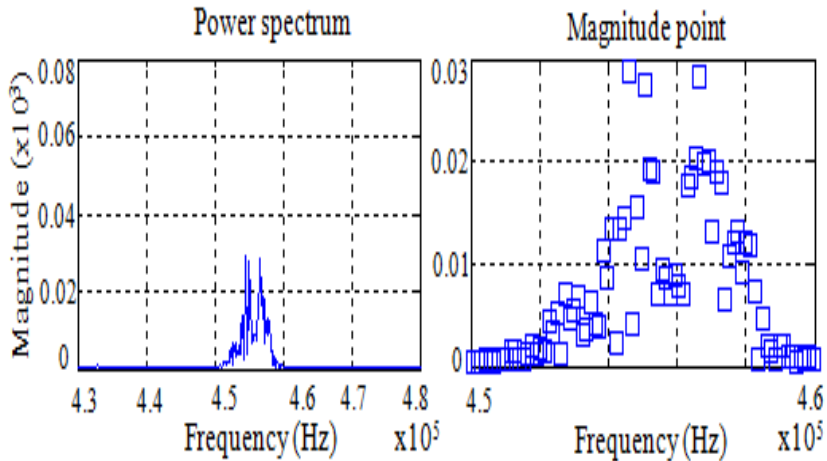

Fig. 3. Power spectrum and magnitude point of the echo signal

The results are presented in scatter plot based on echo power value. The fish echo power strength represented by circle symbols and green turtle represented by triangle symbols (Fig.4). The power value of sea turtle is obtained from head, side and tail angle, while fish is taken at head, lateral and tail from 1meter to 3 meter distance. From the graph, it is obviously show that echo power are overlapped each other. However, there is some value of turtle located above the fish echo level.

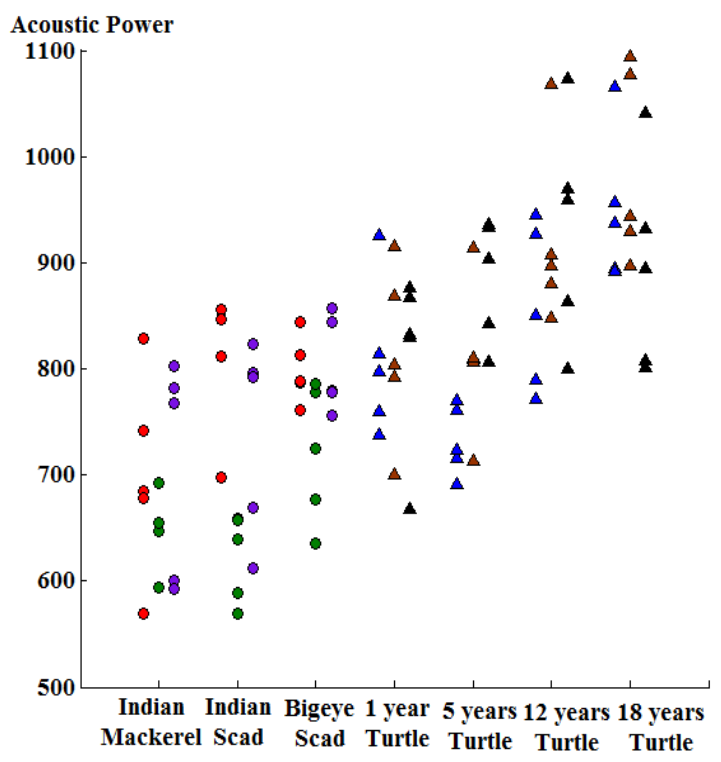

Fig. 4. Echo power comparison at 1 meter to 3 meter distance.

Based on the Fig. 5, the result revealed that there are significant different between green turtle and fish mainly for 12 years and 18 years turtle (in the dashed line circle). The acoustic power has been plotted for 3 meter to 5 meter distance. The difference value obtained at 4.5 meter and 5 meter distance. 
Most of the value located above fish echo level in range 900 to 1300 . From the graph, we also found that acoustic power range of fish is between 500 to 900 .

Scatter value for fish demonstrate echo strength are different and also depend on angle of measurement. Observation on Indian Mackerel species show lateral side contributed high value compare to other side. Moreover, the lowest value of fish obtained is from their tail side, which is as we know have small shape.

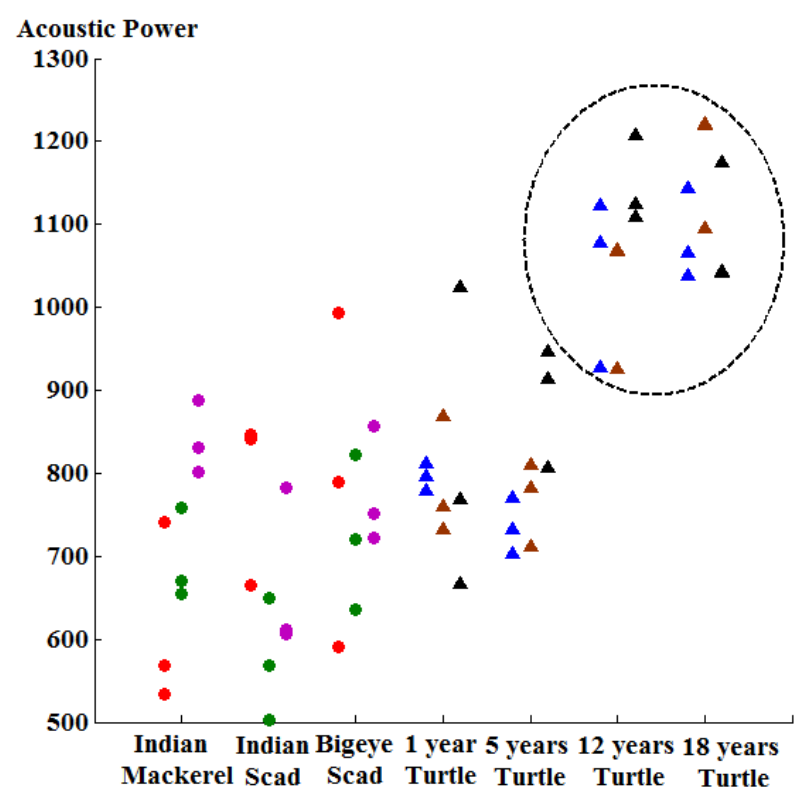

Fig. 5. Echo power comparison at 3 meter to 5 meter distance.

The comparison between fish and turtle at carapace and plastron angle are shown in Fig. 6. The carapace echo power value represented by blue circle and plastron in brown circle. Although, result for head, tail and side angle not show different for all turtles, but comparison the echo power value for the carapace and plastron shows the results otherwise. The highest power recorded is from 18 years turtle plastron, which is contributed 2207.23. Most of the value obtained from this angle located above 1000, which is higher compared to fish. These finding indicated that side gives high backscattering strength compare to other side.

One of the reasons behind of this event is a sound covering a broad surface of the carapace and plastron. Other than that, the high value obtained may also because of the hard surface of the carapace and plastron.

\section{CONCLUSIONS}

The results demonstrate the capability of modified echosounder to detect sea turtle and some species of fish. Measurements were made from all different angles from 1 meter to 5 meter distance, in order to find the difference echo range between that marine animal. The experimental results show that, there is significant difference between fish and turtles aged 12 to 18 years at 4.5 meter and 5 meter distance and not significant for age 1 to 5 years.

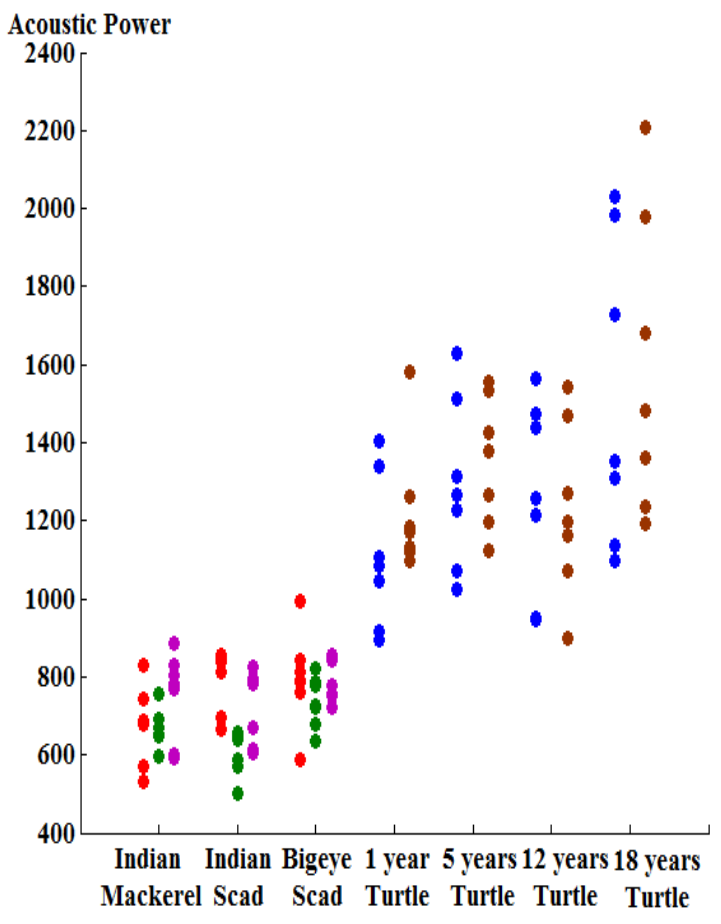

Fig. 6. Echo power comparison between fish and turtle at carapace and plastron angle

Besides that, results also show overlap happened at 1 meter to 3 meter distance for both animals. This condition may occur due to the sound beam aperture is too small at that distance and cause sound energy is focused on the same surface. However, this finding is considered important in determining the best method of separating them from other animals. Other than that, through this result, it revealed that size, surface and animal angle play important role to determine acoustic strength value. Based on the result, we can conclude that by using this method we can separate adult turtle and fish, especially for adult turtles that are frequently victims by fishing vessel. Although the study show significant result, but further research must be conduct for different species of fish, in order to ensure there are no overlap value between sea turtle and fish. Additionally, experiments are carried out on the dead fish, so another experiment on live fish is proposed to ensure that the values obtained accurate. This study only focused measurement in the fiber tank, which is limited space and distance. Although, we get the clean signal without interference from tank wall, but the maximum range of experiments that can be performed is limited to 5 meter position. Therefore, further research suggested conducting in large space such as pool and sea.

\section{ACKNOWLEDGMENT}

We thank TUMEC staff for expert sharing especially in handling turtle and providing facilities during experiment. We also want to thank people who involved in the experiment directly or indirectly to make sure the success of this study and not forgetting to Electrical \& Electronic Engineering Faculty, Universiti Malaysia Pahang because providing a good learning environment and encourage a culture of research and innovation among students. 


\section{REFERENCES}

[1] C.J. McDaniel, L.B. Crowder, and J.A. Priddy, "A spatial analysis of sea turtle abundance and shrimping intensity in the U.S Gulf of Mexico," Proceedings of The Nineteenth Annual Symposium On Sea Turtle Conservation and Biology, 1999.

[2] R. Arauz, "Implementation of the turtle excluder device (TED) by the shrimp fleet of Pasific Central America," Proceedings of The Eighteenth International Sea Turtle Symposium, 2000.

[3] D.T. Crause," After TEDs : What's next," Proceedings of The Eighteenth International Sea Turtle Symposium, 2000.

[4] E. Gilman, J. Gearhart, B. Price, S. Eckert S, H. Miliken, J. Wang, Y. Swimmer, D. Shiode, O. Abe, S.H. Peckham, M. Chaloupka, M. Hall, J. Mangel, J.A. Shigueto, P. Palzell, and A. Ishizaki, Fish and Fisheries, 2010, Vol. 11, pp57-88.

[5] J.W. Valdemarsen, and P. Suuronen," Modifying fishing gear to achieve ecosystem objectives,'Conference on RESPONSIBLE FISHERIES IN THE MARINE ECOSYSTEM, 2001, Iceland.

[6] R.L Lewisson, L.B. Crowder, and D.J Sharer," The impact of turtle excluder devices and fisheries closures on Loggerhead and Kemp's Ridley stranding in the Western Gulf of Mexico," Conservation Biology, vol. 17 n. 4, 2003, pp. 1089 - 1097.

[7] A.Yudhana, J. Din, S. Abdullah, Sunardi, "Sound stimulus for detection turtle hearing Threshold," International ConferenceInformation \& Communication Technology and System, August $19-21,2008$, Bandung.

[8] S.P Epperly, "Fisheries related mortality and turtle excluder devices (TEDs),’The Biology of Sea Turtles, vol. 11, 2003, pp. 339 - 353.

[9] B.J Gallaway, J.G. Cole, J.M. Nance, R.A. Hart, G.L. Graham, "Shrimp loss associated with turtle excluder devices : Are the historical estimates statistically biased,"North American Journal of Fisheries Management, vol. 28, 2008, pp. 203-211.

[10] J.G. McGilvray, R.P. Mounsey, MacCartie, “The AusTED II, an improved trawl efficiency device 1.Design theories", Fisheries Research 40 (1999) 17-27.

[11] P. Casale, L. Laurent, G. De Metrio, "Incendental capture of marine turtles by the Italian trawl fishery in the north Adiatic Sea," Biological Conservation 119 (2004) 287-295.

[12] A. Yudhana, Sunardi, J. Din, S. Abdullah, and R.B.R. Hassan, "Turtle hearing capability based on ABR signal assessment," TELKOMNIKA : Indonesian Journal of Electrical Engineering, 2010, Vol. 8(2), pp. 187194.

[13] M. Lenhardt, "Marine turtle acoustic repellent/alerting apparatus and method," Reviews of Acoustical Patents Journal Acoustical Society of America, vol. 112 n.5, 2002.

[14] S. Sarangapani, J.H. Miller, G.R. Potty, D.B. Reeder,T.K. Stanton, D. $\mathrm{Chu}$, "Measurements and modeling of the target strength of divers,"Oceans 2005 - Europe, vol. 952, 2005, pp. 952 - 956.
[15] T.K. Stanton, D. Chu, M. Jech, D.I. James, “ New broadband methods for resonance classification and high resolution imagery of fish with swimbladders using a modified commercial broadband echosounder,'ICES Journal of Marine Sciences, 2010 pp. 365 - 378.

[16] K. Abe, K. Sadayasu, K. Sawad, K. Ishii, Y. Takao, "Precise target strength measurement and morphological observation of juvenile Walleye Pollock (Theragra Chalcogramma)," MTTS/IEEE TECHNO OCEAN '04, vol. 1, 2004, pp. 370 - 374.

[17] K.J. Benoit Bird, W.W.L Au, "Echo strength and density structure of Hawaiian Mesopelagic boundary patches,'J. Acoust. Soc. Am., vol. 114, 2003, pp. 1888 - 1897.

[18] J. Frouzova, J. Kubecka, "Changes of acoustic target strength during juvenile Perch development," Fisheries Research, vol. 66, 2004, pp. 355 -361 .

[19] Sunardi, A.Yudhana, J. Din, R.B.R. Hassan, "Fish species identification based on its acoustic target strength using in situ measurement,"Aquaculture, Aquarium, Conservation \& Legislation International Journal of The Bioflux Society, vol. 3 n. 3, 2010, pp. 195209.

[20] W.W.L. Au, and K.J. Benoit Bird, "Acoustic backscattering by Hawaiian lutjanidsnappersl.” J. Acoust. Soc. Am. Vol. 114(5), 2003.

[21] J.H. Miller, D.C. Potter, “Active high frequency phased array sonar for whale shipstrikeavoidance: target strength measurements,"MTS/IEEE Conference And Exhibition, vol. 4, 2001, pp. 2104 -2107.

[22] K.J. Benoit Bird, and W.W.L Au, "Prey dynamics affect foraging by a pelagic predator (StenellaLongirostris) over a range of spatial and temporal scales,"Behavior Ecology Sociobiology, vol.53, 2003b, pp. $2104-2107$.

[23] T.K. Stanton, P.H.Wiebe, D. Chu, "Difference between sound scattering by weakly scattering spheres and finite length cylinders with applications to sound scattering by zooplankton," J. Acoust. Soc. Am., vol. 103 n.1, 1998.

[24] T. Mukai, K. Lida, Y. Ando, H. Mikami, Y. Maki, R. Matsukura, "Measurements of swimming angles, density and sound speed of the krill Euphausia Pacifica for target strength estimation,"MTTS/IEEE TECHNO - OCEAN '04, 2004, pp. 383 - 388.

[25] T.K. Stanton, “On acoustic scattering by a shell covered seafloor,'J. Acoust. Soc. Am. Vol. 108 n. 2, 2000.

[26] T.K. Stanton, D. Chu, P.H. Wiebe, R.L. Eastword, J.D. Warren, "Acoustic scattering by benthic and planktonic shelled animals," J. Acoust. Soc. Am., 108(2), 2008.

[27] J.D. Warren, T.K. Stanton, D.E. McGehee, D. Chu, "Effect of animal orientation on acoustic estimates of zooplankton properties,'IEEE Journal of Oceanic Engineering, vol. 27, 2002, pp. 130 - 138.

[28] A. mahfurdz, Sunardi, H. Ahmad, Target strength of underwater objects using echo voltage reference, International Journal of Computer and Communication Engineering, Vol. 1, No. 4, 2012. 